This item was submitted to Loughborough's Research Repository by the author.

Items in Figshare are protected by copyright, with all rights reserved, unless otherwise indicated.

\title{
Maintenance performance evaluation of offsite and in situ bathrooms
}

PLEASE CITE THE PUBLISHED VERSION

PUBLISHER

(C) Emerald

VERSION

AM (Accepted Manuscript)

LICENCE

CC BY-NC-ND 4.0

\section{REPOSITORY RECORD}

Pan, Wei, and Alistair G.F. Gibb. 2019. "Maintenance Performance Evaluation of Offsite and in Situ Bathrooms". figshare. https://hdl.handle.net/2134/6185. 
This item was submitted to Loughborough's Institutional Repository (https://dspace.lboro.ac.uk/) by the author and is made available under the following Creative Commons Licence conditions.

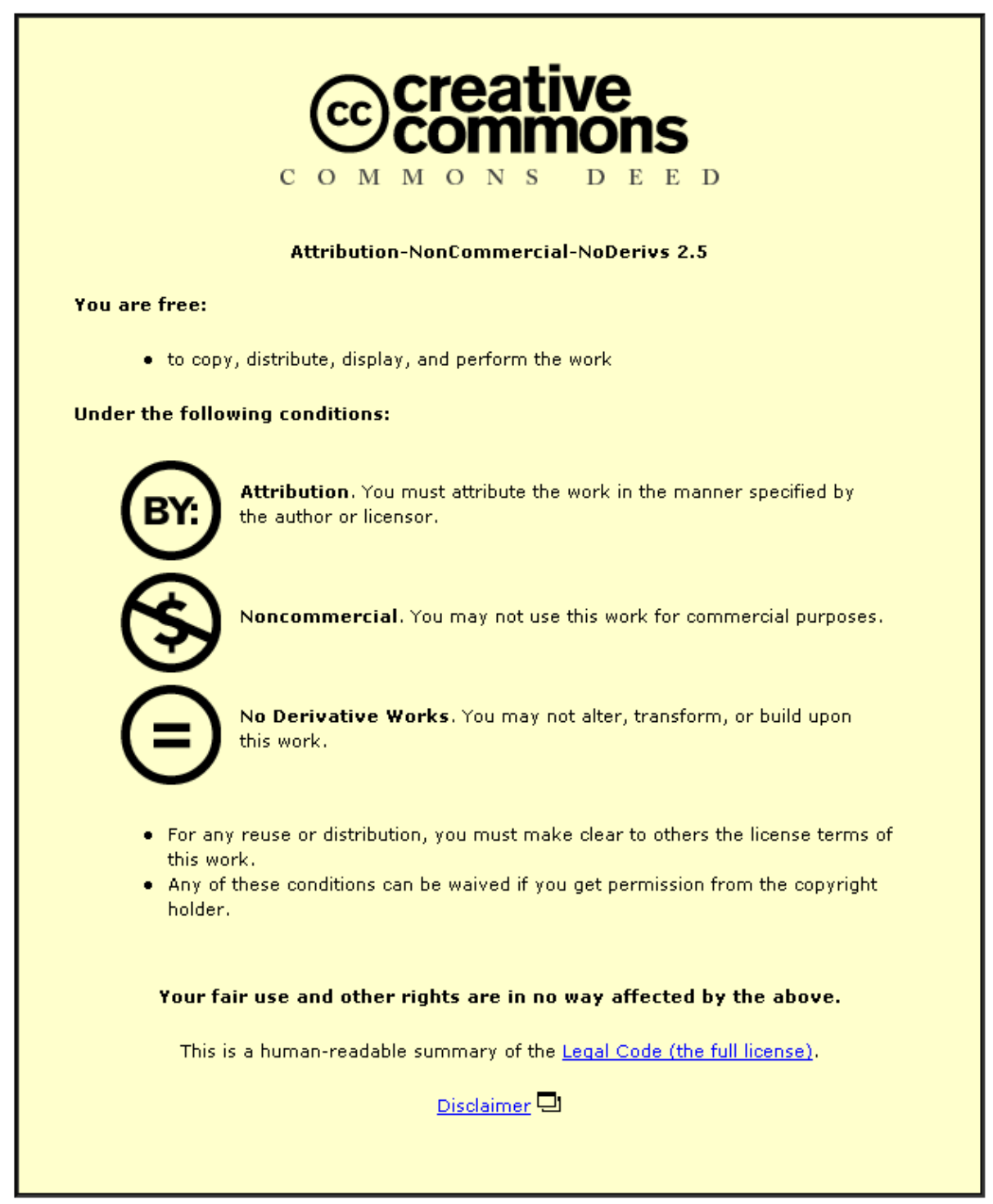

For the full text of this licence, please go to: http://creativecommons.org/licenses/by-nc-nd/2.5/ 


\title{
Maintenance performance evaluation of offsite and insitu bathrooms
}

\author{
WEI PAN ${ }^{1} *$ and ALISTAIR G. F. GIBB ${ }^{2}$ \\ ${ }^{1}$ School of Engineering, University of Plymouth, Plymouth, UK \\ ${ }^{2}$ Department of Civil and Building Engineering, Loughborough University, \\ Loughborough, UK
}

\begin{abstract}
Purpose - Offsite is one of the main innovative techniques employed in the contemporary UK construction sector. Building maintenance accounts for over $5 \%$ of the UK's gross domestic product of which bathrooms are regarded as a critical area, with potential high risks and defects. However, the importance of its maintenance has been largely underestimated and research into this area appears to be limited. This paper aims to address this knowledge gap by investigating the maintenance performance of offsite and insitu bathrooms for student accommodation.
\end{abstract}

Methodology/Approach - The paper examines 732 maintenance records over three years of 216 precast concrete modules, 84 Glass Reinforced Polyester (GRP) modules and 96 traditionally-built insitu bathrooms.

Findings - The research found that offsite modules outperformed insitu bathrooms in terms of maintenance. GRP modules created the least maintenance problems, compared to precast modules and insitu bathrooms. The maintenance of insitu bathrooms was more complex than offsite modules, and involved more diverse problematic areas. The main causes of the problems included inappropriate design, poor build workmanship, lack of quality of component materials and improper usage by occupants. This supports a parallel study by the authors that found that the costs associated with maintenance were significantly higher for insitu bathrooms than for the equivalent offsite solutions.

Research limitations/implications - The paper contributes to understanding the problems of offsite bathroom modules requiring maintenance in comparison with insitu bathrooms and their possible causes. Key aspects of offsite bathrooms including drainage, toilets, vents and sinks should be improved. Quality of component materials used for insitu bathrooms should be ensured. These improvements can only be achieved through better design for maintenance with clients' aspiration embodied. The findings should assist in design decision-making of selecting bathrooms for residential buildings. However, a balanced approach, taking into account other factors for such selection, is open for future investigation.

Originality/Value - The framework of strategies developed should improve the innovative design of bathrooms manufactured offsite and help maintain them for better lifecycle performance.

Keywords: bathroom pods, design, innovation, maintenance, offsite, performance evaluation.

Paper type: Research paper

Please cite this paper as: "Pan, W. and Gibb, A.G.F. (2009) Maintenance performance evaluation of offsite and insitu bathrooms. Construction Innovation: Information, Process, Management - Special Issue on Offsite Manufacturing, 9(1), 7-21.

*Author for correspondence. E-mail: wei.pan@plymouth.ac.uk 


\section{Introduction}

Offsite is one of the main innovative techniques employed in the contemporary UK construction sector (Buildoffsite, 2006). Bathroom pods have been in limited use since the second half of the last century. However, they are still considered innovative by many design teams and have not been fully accepted by clients and their professional advisors (see e.g. Mann, 2006 and Pan et al., 2008).

Building maintenance accounts for over 5\% of the UK's gross domestic product, equivalent to over $£ 30$ billion a year, which makes it one of the largest industries in the UK economy (Wordsworth, 2001). However, the importance of maintenance has been largely underestimated as it has been regarded as unproductive (Seeley, 1987). The fact that buildings would deteriorate rapidly without proper maintenance has been largely overlooked. As one of the key areas of a building, bathrooms were identified to be critical for maintenance due to significant maintenance risks and a likely association with a high number of defects (see Ramly et al., 2006). Annual maintenance cost for wet areas can range from $35 \%$ to $50 \%$ of the total maintenance cost of a building though such areas are usually not more than $10 \%$ of the building gross floor area (Chew and De Silva, 2003). This causes great dissatisfaction of occupants and significant long-term costs for clients.

Despite all these facts, there is a lack of understanding of the maintenance problems of utilising bathrooms manufactured offsite. This affects the design decision-making of what types of bathrooms to use and inhibits an increased uptake of offsite technology in the industry. This paper reports on research into the maintenance of offsite modules in comparison with traditionally-built insitu bathrooms for student accommodation. The paper focuses on examining the problems, investigating their possible causes and developing strategies for improving performance. A detailed analysis of the cost implications of maintaining different types of bathrooms is carried out in a parallel study (Pan et al., 2008). The findings of this paper will improve the design of bathrooms manufactured offsite and also aid in design decision-making of selecting appropriate types of bathrooms to achieve clients' aspirations as well as end-users' satisfaction.

\section{Building maintenance: Definitions \& importance}

Maintenance is generally described as the work undertaken to keep or restore a facility to an acceptable standard (Boussabaine and Kirkham, 2004). A simple definition of building maintenance is to keep a building in a condition appropriate to its use (El-Haram and Horner, 2002). Seeley (1987) defined maintenance as the combination of all technical and associated administrative actions intended to 'retain' an item in, or 'restore' it to a state in which it can perform its required function. Son and Yuen (1993) explained that the term 'retain' means the defects that are prevented from developing by carrying out work in anticipation of failure, whilst the term 'restore' means that minor defects are allowed to occur before they are corrected. This explanation highlights the two main types of maintenance, reactive maintenance, which is to 'restore', and planned maintenance, which is to 'retain' (Spedding, 1994). Reactive maintenance focuses on reported defects and problems by the end user to the maintenance team. This is the same as repairs maintenance as repairs are done as a reaction to the work requirement (Higgins et al., 1995). Planned maintenance is also called predictive or preventative, which is carried out in 
accordance to a plan, even if there is nothing wrong with the equipment or property (Spedding, 1994).

Total spending on building maintenance in the UK has increased by $66 \%$ in the last 10 years (see El-Haram and Horner, 2003). The research by the Royal Academy of Engineering (Evans et al., 1999) demonstrated that the cost of operating and maintaining a building can be appropriately five times the cost of capital over the life of the building. Therefore, to understand building maintenance is important. This is considered to be more critical for buildings constructed using offsite technologies given their current low market share (Buildoffsite, 2006) and the existing reluctance to using such technology (Pan et al., 2007).

\section{Offsite bathroom modules: The concept \& utilisations}

Offsite bathroom modules, often called 'bathroom pods', are manufactured to create a volume of usable space, built and tested within factory conditions (Gibb, 1999). Neale et al. (1993) described prefabricated bathroom modules as ready-to-use building elements as they come fully fitted with all fixtures and fittings and are commissioned ready for use. Though most manufacturers use different production methods, bathroom modules are generally available in timber frame, light steel frame, hot rolled steel frame, concrete or Glass Reinforced Polyester (GRP) structure, with suspended timber floor deck and plasterboard ceiling, and walls are generally plasterboard lined (National Centre for Excellence in Housing, 2006).

The 1960s saw an increased use of offsite bathrooms including examples such as 'clip-on bathrooms' used by Rochdale Local Authority (see Neale, 1993). These bathrooms were made under factory conditions and lifted into place onto prepared foundations at the back of houses. Although this utilisation was not fully integrated into the construction process, it provides a good early example of how offsite bathroom modules were used for housing. Early 1980s saw major developments of modular bathrooms which had previously been used in the Housing Act but with little success. From late 1980s, the usage of offsite bathroom modules has increased steadily as more projects have taken the idea on board. Also, the benefits of offsite modules have been increasingly demonstrated, including improved quality, reduced on-site duration, mitigated risks to health \& safety and savings of costs incurred through snagging. Previous statistics suggest that the money spent on offsite bathroom/toilet modules/pods was around £25 million in 1989 (see Gibb, 1999). This, in itself, was relatively small, but it accounted for $30 \%$ of overall UK building services spending on offsite in that year with the total amount of $£ 84$ million (ibid). The use of bathroom and toilet pods is gathering momentum as offsite manufacture is being championed as the solution for the procurement of all large volume construction outputs in the established markets such as hotels, student accommodation and the Ministry of Defence $(\mathrm{MoD})$ and health sectors of the UK industry (Davis Langdon and Everest, 2004; Gardiner and Theobald, 2005). A survey of large new-build commercial office projects (more than $100,000 \mathrm{ft}^{2}$ ) reported that $20-30 \%$ of such schemes are using offsite toilet modules (see Gardiner and Theobald, 2005).

Given an increasing interest in using offsite technologies, anecdotal arguments on the benefits and problems of offsite bathrooms abound. However, there seems to be a lack of quantitative understanding of maintaining offsite bathroom modules. This is 
significant as it inhibits an increased uptake of such technology in the industry despite their widely-documented potential benefits (see e.g. Gibb, 1999; Blismas et al., 2006; Pan et al., 2007). Also, few of previous studies of 'wet areas' and bathroom or toilet pods (e.g. Chew and De Silva, 2003; Gardiner and Theobald, 2005) have presented comparative analysis between offsite and insitu bathrooms. The lack of comparative performance data inhibits proper interpretation of the benefits from using offsite bathrooms. The case of examining bathroom maintenance problems is also emphasised by the increasing interest in improving bathroom conditions (Bathroom Manufacturers Association (BMA), 2006). Within this context, this paper aims to contribute to knowledge and strategies for improving the maintenance performance of offsite bathroom modules. This has been achieved by examining the maintenance problems and exploring their possible causes of utilising precast concrete and GRP bathroom modules, which is carried out in comparison with traditionally-built insitu bathrooms.

\section{Methodology}

To achieve the research aim, 732 maintenance job records for 396 bathrooms, including offsite modules and traditionally-built insitu bathrooms (Table 1), were investigated in depth.

(Take in Table 1 here)

Case study methods were used for bathrooms in four student accommodation residences in the same university across three consecutive years after their defects period. In this study, the 'bathrooms' were all en suite and comprised a shower, toilet and washbasin. These four residences were selected for this study for their comparability. Exploring the constants and variables of these three cases (Table 2) enabled the achievement of a reasonable 'like-for-like' comparison between the maintenance performance profiles of bathrooms.

(Take in Table 2 here)

Residence A was built in 1992 with 216 en suite bathrooms. These bathrooms were initially designed to be built using traditional methods. However, due to the time constraints of the project, this decision was changed to using offsite methods. The main contractor chose precast concrete bathroom modules. These modules were fully completed in factory, with only the connections to building services to be made on site following the installation. The use of bathroom modules facilitated on-time completion of this project. Residence B had no major alterations until the mid 1990's when the university required a fast and effective way of bringing old halls of residence up to a modern standard. GRP bathroom modules were chosen as they were regarded as a relatively cost-effective method of updating each room and boasting a quick installation with little alteration to the existing building. These modules were also fully completed in factory, with only the connections to building services to be made on site. There were 84 bathroom modules in total installed in this residence. Residence $C$ and $D$ each comprise two blocks, with each block having 24 rooms. Each room was traditionally fitted with an en suite bathroom. These bathrooms used a combination of concrete block walls and dry-lined partitions with sanitary ware, plumbing, fixtures, fittings, services and tiling all installed on site. These 96 bathrooms, in total, were combined as one case study of traditionally-built insitu bathrooms. 
For the case studies, quantitative data were collected by investigating the maintenance records retained by the Estates Department of the University. A database using Microsoft Excel spreadsheets was created, in which specific job numbers of records were stored to ensure that the maintenance problems could be tracked back to their records. This ensured the accuracy of data analysis and provided reliable tracking to original data. All maintenance records were also assessed to determine the nature of the problems, and subsequently categorise and compare them. The data were collected for three consecutive years after the 12month defects period, which ensured that the data collected were of maintenance work carried out by the university. Study over the period after that would help produce more informative result. However, that, if any, is out of the scope of this paper. It would also be impractical for this research to handle given the time and resources available.

Both quantitative and qualitative data were provided where available. This helps to neutralise bias of the use of any single method (Creswell, 2003), to minimise the degree of specificity of certain methods (Gillham, 2000) and to provide insight into different levels or units of analysis (Tashakkori and Teddlie, 1998). Four semistructured interviews with the suppliers of the bathroom modules and the maintenance officials in the university's Estates Department were carried out to verify the results and explore the possible causes of the problems. The interviews were recorded and transcripts were analysed. For quantitative analysis, the criterion ' $\%$ of overall problems' was used for identifying the most significant problematic areas. Descriptive statistical analysis was used, in the form of univariate analysis (with one variable) (see Bryman, 2004), from which meaningful results were obtained and their implications were interpreted.

\section{Analysis and results}

The data collected were analysed comparatively. The most significant problematic areas of each type of bathrooms were identified and investigated. For analysing the quantitative data and interpreting the results, two performance measures have been developed in this paper. They are "number of reported problems per 100 bathrooms" and "recorded problems as a percentage of overall problems".

\section{Comparative problem analysis}

The investigation into the maintenance records shows that the problems of bathrooms for maintenance varied in terms of both volume and type. The numbers of reported problems, both overall and breakdowns across the three years studied (see Table 3), are converted into the numbers of reported problems per 100 bathrooms (Figure 1). This conversion of results enabled a reasonable and consistent comparison between the types of bathrooms in terms of the frequency of reported problems.

\section{(Take in Table 3 here) \\ (Take in Figure 1 here)}

The GRP bathroom modules had the smallest number of reported problems for the three years in total (130 per 100 bathrooms), whilst the numbers for precast concrete modules and traditional insitu bathrooms were much larger, 195 and 199 respectively (Figure 1). In terms of the number of problems in the individual years, the GRP modules were, again, associated with the smallest numbers, i.e. 50 per 100 
bathrooms or less (Figure 1). The other two types of bathrooms had more changeable numbers of problems across the three years. Traditional insitu bathrooms had the largest number of reported problems per 100 bathrooms in Year 1 (80), whilst that dropped substantially in Year 2 (68) and in Year 3 (51). However, the number of reported problems with concrete modules became the largest in Year 2 (75) and Year 3 (59) though that was much smaller than that of traditional insitu bathrooms in Year $1(61)$.

\section{Detailed analysis of precast concrete modules (Residence A)}

The most problematic area was drainage, contributing around a third to the total number of recorded problems for all the three years. This was followed by toilets (20\% of all problems) and vents (14\% of all problems) (Figure 2). These top three problematic areas, together, accounted for around two thirds of the problems in total. Considerable problems also existed with other areas such as shower heads/controller units $(9 \%)$ and sink $(9 \%)$. There was a noticeable number of problems with doors in Year 1 (11\% of all recorded problems), but that dropped significantly over the following two years. The numbers of recorded problems with other areas were modest (less than 5\%).

(Take in Figure 2 here)

\section{Detailed analysis of GRP modules (Residence B)}

The most problematic area was toilets, which contributed a third or so to the total number of recorded problems for all the three years (Figure 3). This was followed by sinks (a quarter of all problems). The problems in Year 1 were largely associated with the toilets. Once this type of problem had been reduced in Year $2 \& 3$, the overall number of problems of GRP modules became consistent, at a level of around 40 problems per 100 bathrooms (Figure 1). Less problems, but still of a considerable amount, existed with other areas including lighting, drainage and vent (above $12 \%$ in Year 2). For the same areas, the numbers of recorded problems were less than $10 \%$ in other two years.

(Take in Figure 3 here)

\section{Detailed analysis of insitu bathrooms (Residence $C \& D$ )}

Traditionally-built insitu bathrooms were associated with a wide range of problems. The area of shower heads/controller units was the most problematic through the three years, contributing a fifth or more to the total recorded problems (Figure 4). This was followed by tile damage, leakage, drainage and lighting, all with recorded problems exceeding $10 \%$ in at least one of the three years. Problems also existed with other areas such as toilets, sinks, water temperature/pressure, but less frequently. (Take in Figure 4 here)

\section{Causes of the maintenance problems}

The investigation of the maintenance records suggests several major issues which contributed to the bathroom problems requiring maintenance. They were also verified and clarified by the suppliers and maintenance officials of the Estates Department through the follow-up interviews. These major issues included design of offsite bathroom modules, specification of component products and materials, build workmanship and usage by occupants. However, it seems to be difficult to identify the specific causes of the problems due to the fact that each one might be caused by a combination of possible reasons. For example, the blockage of drainage might be 
caused by the under-designed drainage pipes, the improper usage by occupants or both. Discussion of these issues is provided in the rest of this paper where applicable.

\section{Discussion}

This paper has contributed empirical evidence to utilising offsite technology. It has investigated the problems of maintaining offsite and traditional insitu bathrooms for student accommodation. The findings of both the comparative study and breakdown analysis of individual types of bathrooms are discussed within the context of existing knowledge.

The maintenance records suggest that a considerable number of the maintenance issues for each of the different bathroom types, those related to occupants' usage for example, were not related to the construction or manufacturing systems. Although consisting of a significant number of installations, this study only considered three different bathroom 'systems'. The results may not apply to all precast, GRP or insitu systems available in the market. Notwithstanding, there were significant differences between the amount and frequency of the problems with the different bathroom types, some of which were affected by the system itself.

The GRP modules had the least average amount of recorded problems per module. This suggests that this system offers a more reliable bathroom solution. Also, a parallel study by the authors (Pan et al., 2008) suggested that the GRP modules had the lowest average cost per module for maintenance. These findings, together, suggest that GRP modules are the most cost-efficient system for maintenance in the types of bathrooms studied. It is consistent with the claims of the manufacturers that GRP modules offer robust interior finishes and enable compact and robust construction and their 'scratch resistant and easy-care surface' satisfies the requirements of applications (see e.g. Saniflex, 2006).

The precast concrete bathroom modules had a much larger average number of recorded problems than GRP modules for all the three years. It should be noted, however, that, in the parallel study (Pan et al., 2008), the cost of the maintenance problems for the precast pods was considerably less than for the equivalent insitu bathrooms. The problems were focused on several areas including drainage, toilets and vents. This was mainly due to the poor design of the drainage systems and lack of quality of component materials and products used for precast modules, which caused a considerable disadvantage for the client and occupants. The client's awareness of the technology used can have a dramatic effect on maintenance. The decision of using precast modules was actually made by the main contractor for achieving a timely completion of the project for the start of the new academic term. The decision was made fairly late in the process and was not communicated well to the client. This example provides a warning that lack of awareness of the limitations of the technology from the client's side may impose significant risks on long-term performance of the facilities.

Traditionally-built bathrooms were identified as the worst performing areas with the largest number of recorded problems. This finding offers strong support for the use of offsite technologies for the applications. Also, the problems were associated with a wider range of areas. The finding is consistent with the results of the study by Chew and Tan (2004) that 14 types of defects were identified in wet areas, of which 
tile debonding, mastic failures and staining of tiles accounted for nearly $60 \%$ of all in frequency. This could be explained by the fact that traditional insitu work tends to be less efficient and productive which may sometimes be of a poor standard. It is, therefore, important to ensure the quality of materials and products used and the workmanship of building the bathrooms. However, traditionally-built bathrooms offered better flexibility and accessibility of installation and maintenance than offsite modules. This was partly due to a greater availability of materials and products for repairs for bathrooms built in a traditional way. In contrast, some items used in the offsite bathroom modules were not readily available in the local market, and some were very special and had to be ordered directly from the manufacturer (Idris, 1998).

Both GRP modules and traditional insitu bathrooms had fewer reported problems in Year 2 and 3 than Year 1, whilst concrete modules had the largest number in Year 2. This was largely due to the increasing amount of problems associated with the drainage and toilet areas within the precast modules. The performance of traditionally-built bathrooms, in terms of the number of reported problems, seemed to be better than that of concrete modules for Year $2 \& 3$. This finding is interesting as traditionally-built bathrooms are generally regarded not as good as offsite modules. Manufacturers claim anecdotally that the maintenance profile of offsite modules is of no difference to traditionally-built bathrooms (see e.g. R B Farquhar, 2006). Maintenance and replacement are even claimed to be eased through the use of offsite, provided the units are appropriately designed (Sparksman et al., 1999; Gardiner and Theobald, 2005). All these, together, highlighted the importance of design in determining the maintenance profile of bathroom modules.

The investigation into the maintenance of offsite bathrooms suggests that the principal causes of the problems were inappropriate design of the modules, lack of quality of component products and materials, poor workmanship of build and repairs, and improper usage by occupants. This is consistent with the findings of previous studies. The study by Chew and Tan (2004) showed that plumbing selection, access for fitting maintenance, material maintainability, usage and construction quality are the most significant parameters associated with the maintainability of wet areas. The research by Ramly et al. (2006) found that design factors, including choice of materials as part of design selection, contributed $47 \%$ to the defects they studied. Other factors included construction (15\%), misuses of facilities (18\%), poor maintenance $(15 \%)$ and vandalism (5\%). Idris (1998) also revealed that some of the maintenance problems could have been minimised by better design and detailing of the building and by improved specification of building materials.

\section{Strategies for improving maintenance performance of offsite bathrooms}

The results of this paper and the discussion within the existing body of knowledge suggest that the maintenance performance of bathrooms can actually be influenced by various factors including design, products \& materials used, clients' awareness, build workmanship and occupants' usage. Based on the learning a framework of strategies is recommended below for improving maintenance performance of offsite bathrooms.

Firstly, the approach 'design for maintenance' needs to be integrated as part of the design strategy for offsite bathroom modules, irrespective of the system chosen and 
equally applied to insitu solutions. This approach should take into account reliability, durability, maintainability and whole-life costing at the design stage (El-Haram and Horner, 2002). This research supports these arguments by providing a practical case embodied with quantitative data. The drainage and toilets problems with offsite bathrooms were largely associated with the design of the modules and could have been addressed at design stages. However, designs of modules can vary substantially from each other, which can cause problems for access and repairs.

Secondly, products and materials specifications, if not provided in design, should be clarified for selecting items for manufacturing bathroom modules. This should help ensure the lifetime performance of products and materials used in offsite modules. For the industry overall, there are few established supply chains for the use of offsite (Davis Langdon and Everest, 2002), in the absence of which, the selection of products and materials will be influenced by the need to ensure quality and availability. Also, as Chew and Tan (2004) recommended, the selection and detailing of waterproofing and plumbing fittings should be integrated into the design. The durability, performance and maintainability of materials should be checked before use.

Thirdly, clients and specifiers need to understand the production technology in order to realise the full benefits of offsite bathrooms on maintenance. An indirect reason for the 'hidden' problem of drainage pipe design of the precast modules was that there was no counterpart design review from the client's side. Therefore, the hidden design problem was not identified when the prototype was made. Previous studies actually highlight that clients and specifiers should commit to the use of offsite technology at an early stage to realise the benefits (e.g. Gibb and Isack, 2003). Ideally, a "customer orientation" philosophy (see Jaworski and Kohli, 1993) should be adopted by offsite solution suppliers so that clients' aspirations are fully appreciated and realised. However, there seems to be a serious lack of organisationwide commitment and response to customers' requirements in the industry (Dulaimi, 2005). The maintenance profile was also affected by the maintenance strategy used by the end-user. The maintenance strategy used by the university in this case study was reactive. In practice, most organisations use reactive or repairs maintenance for their properties as predictive maintenance absorbs funding on something that has not yet gone wrong and the return is not instant and is hard to distinguish (see Levitt, 2003). Therefore, in this context, the study suggests that clients should take a more proactive role to verify the technology in order to avoid 'hidden' design problems.

Fourthly, it is important to ensure a delivery of quality build and installation of bathroom modules to improve their lifecycle performance. This should include areas like transportation and on-site handling, tolerances for fitting into the structure, the accessibility of hidden services and the ease of replacement of ancillary components, the standards applicable to bathrooms including all relevant laws, regulations, standards and codes, notably concerning water installations, ventilation installations and electrical installation (Waterman, 2006). The importance of ensuring construction quality was also emphasised by Chew and Tan (2004) for improving the maintenance of wet areas. This seems to be significant given the current acute skills shortage in the industry fuelled by sustained regional growth, which contributes to the depletion of build quality (Dainty et al., 2004; Anumba et al., 2005). Though bathroom modules should have superior embedded quality than traditional insitu 
bathrooms as the modules are manufactured in factory-controlled conditions, the workmanship for their installation and repairs should be guaranteed.

Fifthly, the efficiency of maintenance and communications between design, build and maintenance teams need to be improved. Idris (1998) recommended that a copy of all technical documents and records during design and construction stages should be provided to the maintenance team. Ramly et al. (2006) suggested that design defects can possibly be avoided by promoting good design team, research and using feedback and records from maintenance teams. The design team should give input based on the client's needs. Maintenance records are important and should be provided to designers so that the same mistakes are not repeated. The "lean thinking" approach (see Kempton, 2006) could be applied for improving efficiency of repairs. Actually, "lean principles" have been widely applied for improving performance of construction processes by reducing non-value adding activities (see Al-Sudairi, 2007). El-Haram and Horner (2002: 117) also provided a strategy for improving efficiency to reduce housing maintenance costs that "reducing the duration of maintenance tasks by increasing the accessibility, planning maintenance resources in advance and training of maintenance staff'. However, as Kempton suggested, lean thinking may be much more difficult to apply to the reactive type of repairs. The university in this study adopted reactive maintenance strategy, which determined the maintenance work was not organised in a planned way, but on an ad hoc basis.

Sixthly, education of occupants for proper usage of bathrooms should also help improve the situation. Previous studies also suggested a direct relationship between the performance of wet areas and repair costs and the nature and level of usage by occupants (e.g. Chew and Tan, 2004; Waterman, 2006). This appears to be more significant for student residential buildings.

Last but not least, a database recording maintenance problems and associated costs should be maintained. Analysis drawing on the database would enable the identification of patterns of maintenance problems and their cost implications. This is significant given the context of the reactive maintenance strategy used by the university, i.e. this would help the university understand the problems better and, therefore, adopt necessary precautions to avoid similar problems in future projects. Also, maintenance performance indicators can be developed from the database for measuring and improving the lifetime performance of bathrooms. Performance indicators can help coordinate, monitor and diagnose maintenance cost issues (Atkinson et al., 1997) and have also been regarded as a key management activity that provides decision makers with the information necessary to make effective decisions, assess performance, and allocate budgets efficiently (Webster and Hung, 1994). The indicators used in this paper, e.g. number of recorded problems per 100 bathrooms per year, provide an example in this regard. There seems to be an increasing interest in studying maintenance performance measurement systems (see Parida and Kumar, 2006) and IT-based lifecycle costing approaches (see Fu et al., 2007) for evaluating performance of construction techniques. The strategy provided in this paper suggests a simpler but more direct approach for collecting and storing maintenance data. This should be more practical for clients who use reactive maintenance and are with less expertise on more advanced database management systems. 
The discussion of the results of this paper within the wide context of existing knowledge and strategies developed for improving bathroom maintenance performance enable the conclusion of this paper, from which future research is also recommended.

\section{Conclusions and future research}

This paper has investigated the maintenance performance of bathrooms in multioccupancy dwellings, in this case, housing university students. The study investigated precast concrete modules, GRP modules and traditionally-built insitu bathrooms in a comparative manner. The research found that offsite modules outperformed insitu bathrooms in terms of maintenance. The GRP modules had the smallest number of recorded maintenance problems, with precast modules and traditional insitu bathrooms being associated with more problems. Toilets and sinks were identified as the major areas of GRP modules for maintenance, whilst drainage, toilets and vents were the most problematic for concrete modules. The problems of offsite athrooms were mainly associated with the design issues of the modules. The maintenance of insitu bathrooms was more complex than offsite modules, and involved wider problematic areas. Having explored the causes of the problems the paper has developed a framework of strategies tackling the design of modules, specification of component products and materials, build workmanship and usage by occupants. The results emphasise the importance of integrating the concept of maintenance into early design stages. The approach of 'designing for maintenance' needs to be embraced. This research provides a worked example of measuring maintenance performance of offsite in a quantitative manner. This is important as it contributes empirical evidence to demonstrating the benefits from using offsite, which will likely encourage the uptake of such technology in the industry. The quantitative maintenance data should help clients and their professional advisors with selecting appropriate types of bathrooms for their projects.

The maintenance performance data were based on student accommodation buildings. Care should be taken for interpreting the results within other built environment sectors. Any quantitative generalisation, or so called 'sampling logic' (see Bryman, 2004), of the findings of this paper needs to be reviewed, but 'the replication logic' (see Yin, 2003) should remain valid. Also, caveats should be made for generalising the findings to the context in which different maintenance strategies are adopted. Further study could be carried out of maintaining bathrooms in different types of buildings, e.g. hotels, offices and housing. This would increase the knowledge of bathroom maintenance in broader areas and reduce any potential bias of views on particular building types. The findings of this paper should help mitigate design problems with bathroom modules and rationalise the selection of bathroom types for residential buildings. However, such a selection may be subject to a range of other factors of consideration like capital cost, design lead-in, installation, transportation, repeatability (see Gardiner and Theobald, 2005; Waterman, 2006). A balanced structured approach is needed, but it is open for future investigation.

\section{Reference}

Al-Sudairi, A.A. (2007) Evaluating the effect of construction process characteristics to the applicability of lean principles. Construction Innovation, 7(1), 99-121. 
Anumba, C., Dainty, A.R.J., Ison, S.G. and Sergeant, A. (2005) The application of GIS to construction labour market planning. Construction Innovation, 5, 21930 .

Atkinson, A., Waterhouse, J. and Wells, R. (1997) A stakeholder approach to strategic measurement. Sloan Management Review, 38(3), 25-37.

Bathroom Manufacturers Association (BMA) (2006) 2006 Market Trends, BMA, Stoke on Trent.

Blismas, N.G., Gibb, A.G.F. \& Pasquire, C.L. (2006) Benefit evaluation for offsite production in construction. Construction Management and Economics, 24(2), 121-30.

Boussabaine, A.H. and Kirkham, R.J. (2004) Simulation of maintenance costs in UK local authority sport centres. Construction Management and Economics, 22(December), 1011-20.

Bryman, A. (2004) Social Research Methods, 2nd Edn. Oxford University Press, Oxford.

Buildoffsite (2006) Offsite Construction Industry Survey. CIRIA Books, Construction Industry Research \& Information Association. London.

Chew, M.Y.L. and De Silva, N. (2003) Maintainability problems of wet areas in high-rise residential buildings. Building Research and Information, 31(1), 60-9.

Chew, M.Y.L. and Tan, S.S. (2004) A multivariate approach to maintenance prediction of wet areas. Construction Management and Economics, 22(May), 395-407.

Creswell, J.W. (2003) Research Design: Qualitative, Quantitative, and Mixed Methods Approaches, 2nd Edn. Sage Publications, Thousand Oaks, California.

Dainty, A.R.J., Ison, S.G. and Root, D.S. (2004) Bridging the skills gap: a regionally driven strategy for resolving the construction labour market crisis. Engineering Construction and Architectural Management, 11, 275-83.

Davis Langdon and Everest (2002) Prefabrication and Preassembly - Cost model. Building, 15 February (6), 67-72.

Davis Langdon and Everest (2004) Off-site manufacturer - Cost model. Building, October (42), 67-72.

Dulaimi, M.F. (2005) The challenge of customer orientation in the construction industry. Construction Innovation, 5, 3-12.

El-Haram, M.A. and Horner, M.W. (2002) Factors affecting housing maintenance cost. Journal of Quality in Maintenance Engineering, 8(2), 115-23.

El-Haram, M.A. and Horner, R.M.W. (2003) Application of the principles of ILS to the development of cost effective maintenance strategies for existing building stock. Construction Management and Economics, 21(3), 283-96.

Evans, R., Haryott, R., Haste, N. and Jones, A. (1999) The long term costs of owning and using buildings, The Royal Academy of Engineering, London.

Fu, C., Kaya, S., Kagioglou, M. and Aouad, G. (2007) The development of an IFCbased lifecycle costing prototype tool for building construction and maintenance: Integrating lifecycle costing to $\mathrm{nD}$ modelling. Construction Innovation, 7(1), 85-98.

Gardiner \& Theobald (2005) Spotlight on toilet pods. Building, 25 November (47).

Gibb, A.G.F. (1999) Off-site Fabrication: Prefabrication, Pre-assembly and Modularisation. Whittles Publishing, Caithness. 
Gibb, A.G.F. and Isack, F. (2003) Re-engineering through pre-assembly: client expectations and drivers. Building Research \& Information, 31(2), 146-60.

Higgins, L.R., Brautigam, D.P. and Mobley, R.K. (1995) Maintenance Engineering Handbook, (eds), $5^{\text {th }}$ Edn. McGraw-Hill, New York.

Idris, M.M. (1998) Assessment of the factors influencing the maintenance programme of a large university building in Riyadh. Construction Management and Economics, 16(6), 673-9.

Jaworski, B.J. and Kohli, A.K. (1993) Market orientation: antecedents and consequences. Journal of Marketing, 57, 53-70.

Kempton, J. (2006) Can lean thinking apply to the repair and refurbishment of properties in the registered social landlord sector. Structural Survey, 24(3), 201-11.

Levitt, J. (2003) Complete Guide to Preventative and Predictive Maintenance, Industrial Press Inc., New York.

Mann, W. (2006) Offsite construction: Contractors lead the offsite drive (Special report). Contract Journal, 1 November 2006, 20-21.

National Centre for Excellence in Housing (2006), http://www.homein.org/page.jsp?id=643, accessed 28/03/2007.

Neale, R., Price, A. and Sher, W. (1993) Prefabricated Modules in Construction: A study of the current practice in the United Kingdom, The Chartered Institute of Building (CIOB), Ascot.

Pan, W., Gibb, A.G.F. and Dainty, A.R.J. (2007) Perspectives of UK housebuilders on the use of offsite modern methods of construction. Construction Management and Economics, 25(2), 183-94.

Pan, W., Gibb, A.G.F. and Dainty, A.R.J. (2008) Leading UK housebuilders' utilization of offsite construction methods. Building Research \& Information, 36(1), 56-67.

Pan, W., Gibb, A.G.F. and Sellars, A.B. (2008) Maintenance cost implications of utilising bathrooms manufactured offsite. Construction Management and Economics, In Press.

Parida, A. and Kumar, U. (2006) Maintenance performance measurement (MRM): issues and challenges. Journal of Quality in Maintenance Engineering, 12(3), 239-51.

R B Farquhar (2006) www.rbfarquhar.co.uk/faqs/faqs.asp\#, accessed 02/01/06.

Ramly, A., Ahmad, N.A. and Ishak, N.H. (2006) The effects of design on the maintenance of public housing buildings in Malaysia - Part two. Building Engineer, May, 34-6.

Saniflex (2006) http://www.saniflex.com/engl/wohnheime1.htm1, accessed 02/01/2006.

Seeley, I.H. (1987) Building Maintenance, MacMillan Press Ltd, Basingstoke, UK.

Son, L.H. and Yuen, G.C.S. (1993) Building Maintenance Technology, MacMillan Press Ltd, London.

Sparksman, G., Groak, S., Gibb, A. and Neale, R. (1999) Standardisation and Preassembly: Adding Value to Construction Projects, Construction Industry Research and Information Association (CIRIA), London.

Spedding, A. (1994) CIOB Handbook of Facilities Management, Longman Group Ltd, London.

Tashakkori, A. and Teddlie, C. (1998) Mixed methodology: Combining qualitative and quantitative approaches, Sage, Thousand Oaks, CA. 
Webster, C. and Hung, L. C. (1994) Measuring service quality and promoting decentring. The TQM Magazine, 6(5), 50-5.

Waterman, A. (2006) Costs: Bathroom fit-outs. Building, 14 February (6).

Wordsworth, P. (2001) Lee's Building Maintenance Management. $4^{\text {th }}$ Edn. Blackwell Science, London.

Yin, R.K. (2003) Case Study Research: Design and Methods, 3rd Edn. Sage, Thousand Oaks, California. 


\section{Tables (in the sequence referred to in the text)}

Table 1 Case study sample of bathrooms and maintenance problems

\begin{tabular}{clcc}
\hline Residence & Type of bathrooms & No. of bathrooms & No. of problems recorded \\
\hline A & Precast concrete modules & 216 & 409 \\
B & GRP modules & 84 & 120 \\
C & Traditionally-built insitu & 48 & 85 \\
D & Traditionally-built insitu & 48 & 118 \\
Total & & $\mathbf{3 9 6}$ & $\mathbf{7 3 2}$ \\
\hline
\end{tabular}

Table 2 Constables and variables of comparative case studies

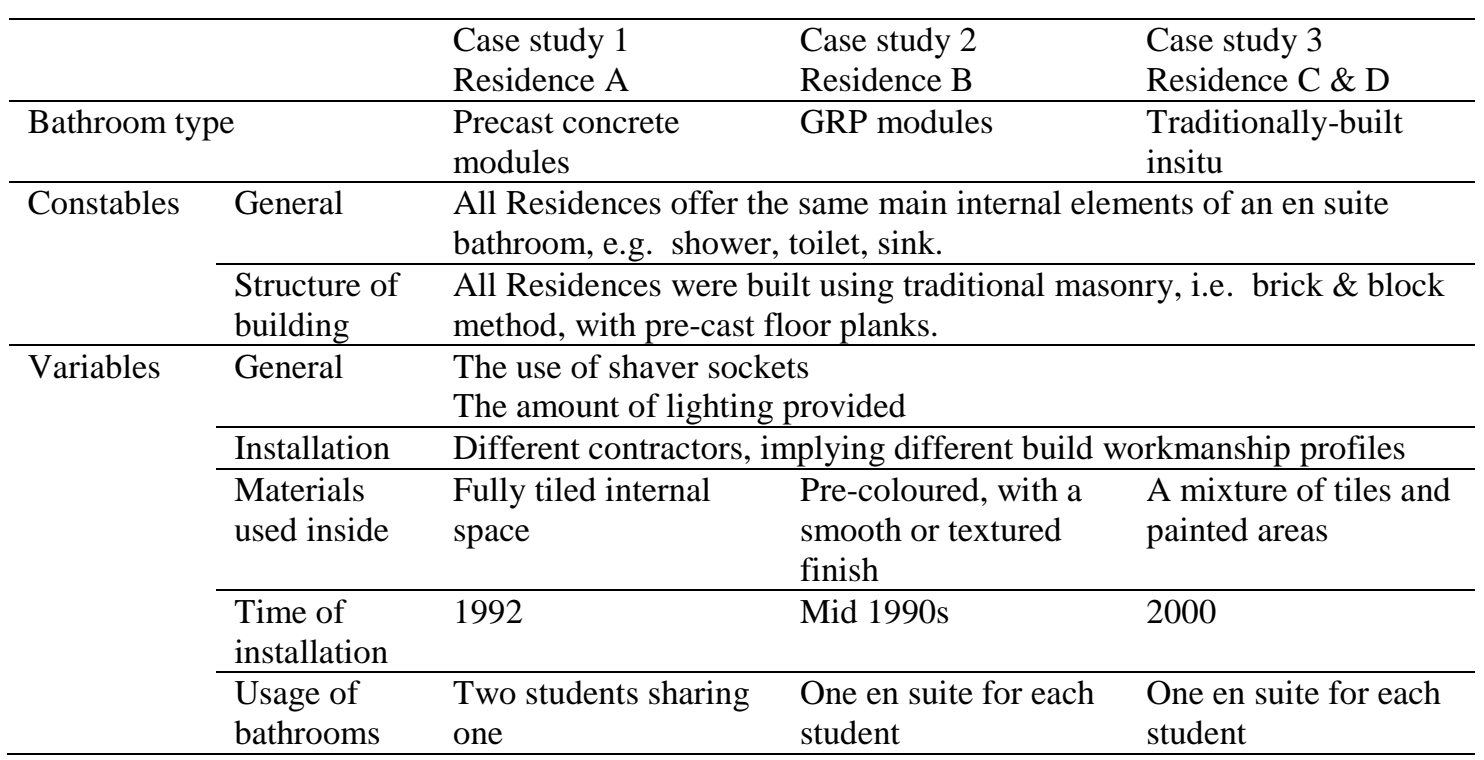

Table 3 Number of reported problems

\begin{tabular}{rccc}
\hline & $\begin{array}{c}\text { Precast Concrete } \\
\text { Modules }\end{array}$ & GRP Modules & Traditional insitu \\
\hline $\begin{array}{l}\text { Number of bathrooms } \\
\text { No. of reported problems } \\
\text { (overall) }\end{array} \quad 216$ & 84 & 96 \\
$\quad$ Year 1 & 422 & 109 & 191 \\
Year 2 & 131 & 42 & 77 \\
$\quad$ Year 3 & 163 & 33 & 65 \\
No. of reported problems & 128 & 34 & 49 \\
(overall) per 100 bathrooms & 195 & 130 & 199 \\
\hline
\end{tabular}


Figures (in the sequence referred to in the text)

Figure 1 Number of reported problems per 100 bathrooms

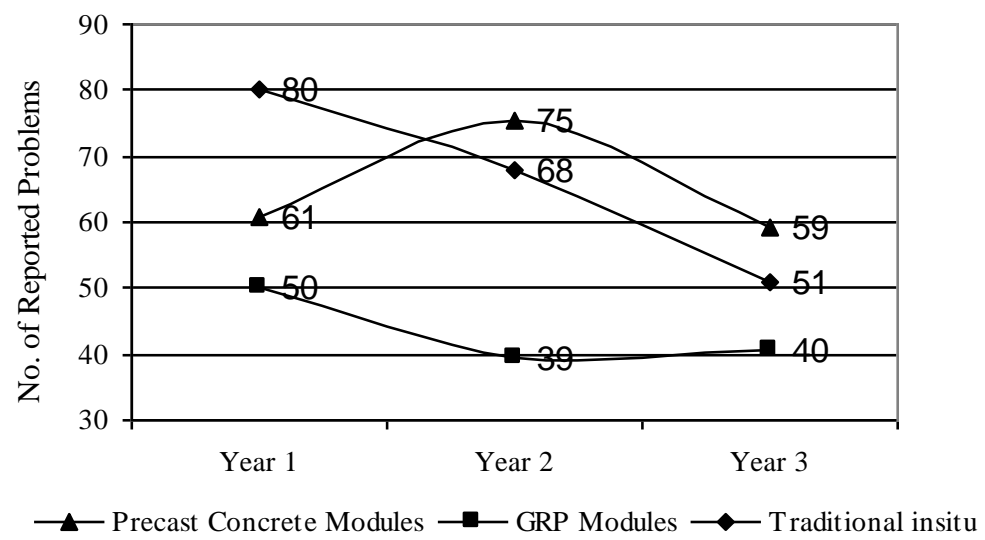

Notes: Precast Concrete modules - Residence A; GRP modules - Residence B; Traditional insitu Residence C \& D

Figure 2 Problematic areas (\% of overall problems) of precast modules

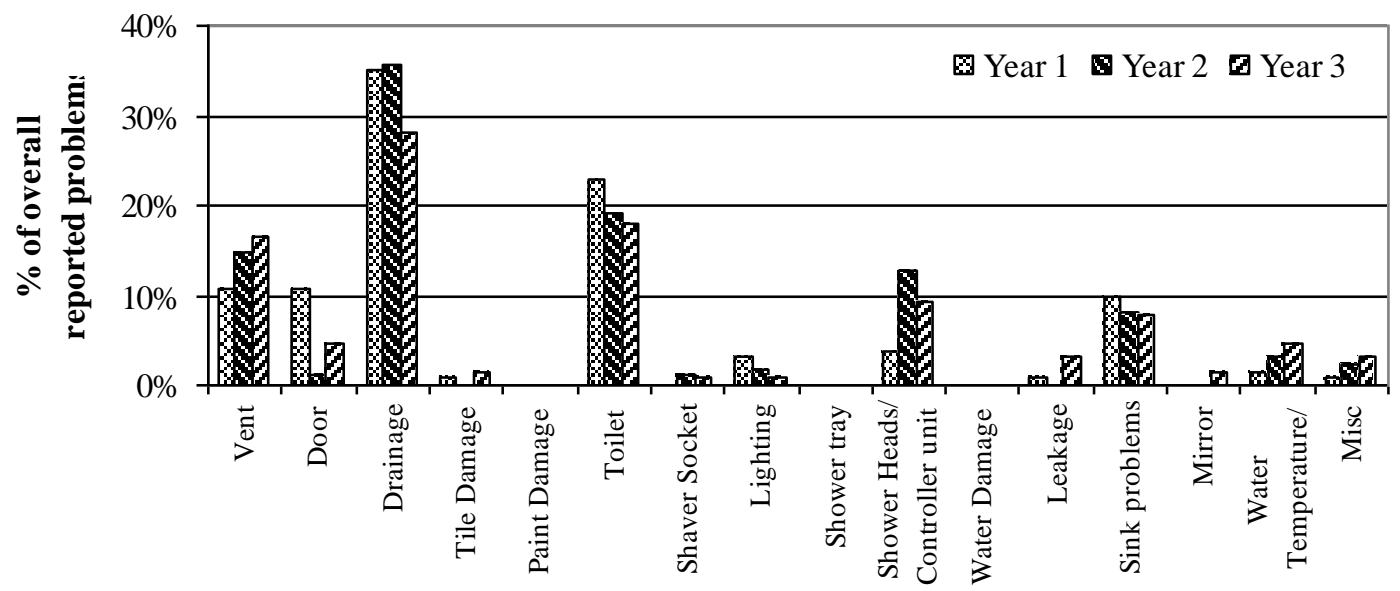


Figure 3 Problematic areas (\% of overall problems) of GRP modules

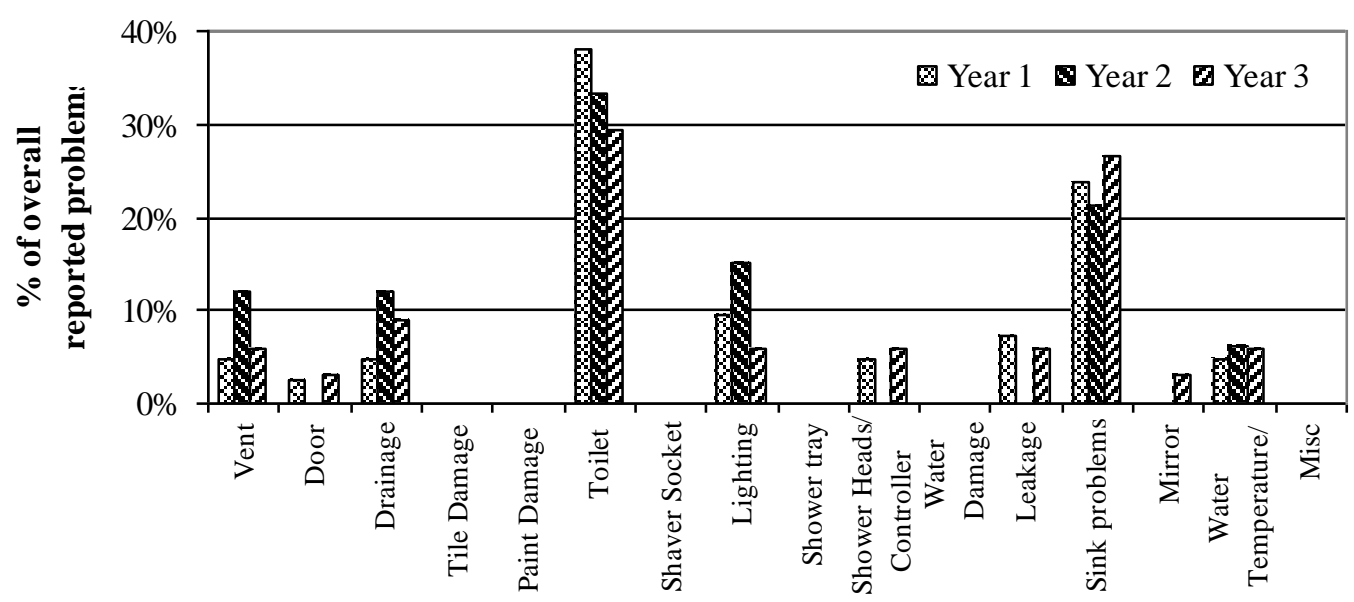

Figure 4 Problematic areas (\% of overall problems) of insitu bathrooms

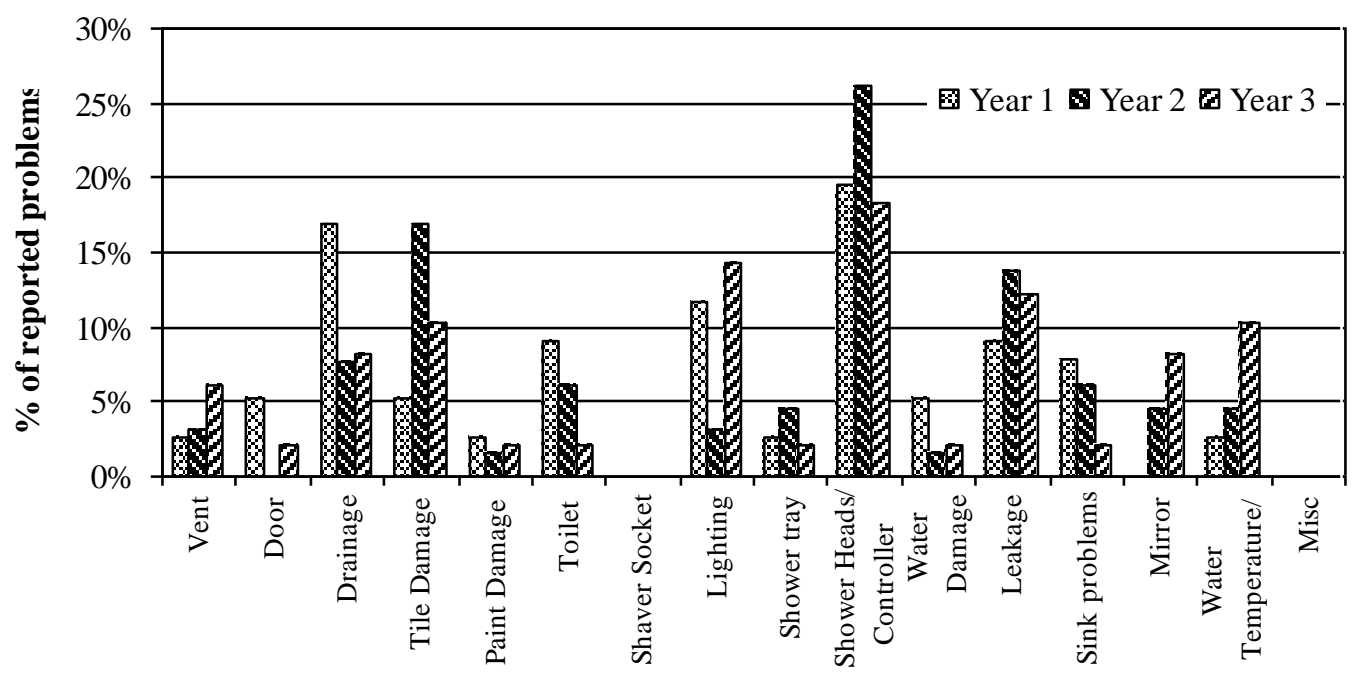

